\title{
Research on Cultivation Mechanism Involving Information Technology Law Talents
}

\author{
Hai-Yan CHEN \\ Dept. of Computer Science and technology, East China University of Political Science and Law, Shanghai \\ 201620, China
}

\begin{abstract}
: with the development of information technology, the related criminal and legal disputes are also increasing, the need of some professionals who know and understand the knowledge of the law and the information technology engaged in related legislation, law enforcement, judicial and other work is urgent. This paper states the training target, the knowledge system, the training methods and the business performance management and the training difficulty of the Information technology law talents, and giving the solution.
\end{abstract}

KEYWORD: the law; the information technology; the compound talents; the training mechanism

\section{INTRODUCTION}

with the rapid development of technology, the traditional fields have been realized informational, such as the traditional commercial develops into the e-commerce, the traditional government office work develops into e-government and so on [1], convenient while in the information, will also bring problems, computer viruses, network attacks, spam, loopholes in the system, network theft, false harmful information and network crimes, how to deal with these crimes, only depends on traditional law is not enough, because they lack of computer knowledge, talents we need have to skilled grasp the computer technology and understand the law either, this is the information technology related legal talent in this paper we talk about. In 2013 Snowden exposure America "prism" incident, [2] to accelerate the network information safety seriously, work related legal and technical means to protect network security is start rapidly, which greatly enhanced the social issues of information technology law talents demand.

\section{TRAINING OBJECTIVES RELATED TO INFORMATION TECHNOLOGY LAW TALENTS}

To meet the needs of society, culture has certain legal basis, and master the basic theory, information technology, basic knowledge and basic skills, appropriate legislation, law enforcement, judicial and other engaged in relevant work related with the information technology in the public security, procuratorial, or court, judicial, law firm, financial, securities, insurance, finance, foreign trade the information technology industry, government, (or IT) and other enterprises and institutions engaged in the design, development of computer system, management and maintenance.

\section{INFORMATION TECHNOLOGY RELATED LEGAL TALENT KNOWLEDGE SYSTEM}

Relevant information technology law talents in addition to legally a solid basic knowledge, but also have a certain theoretical and practical knowledge of information technology, the specific knowledge structure diagram as shown in Fig. 1:

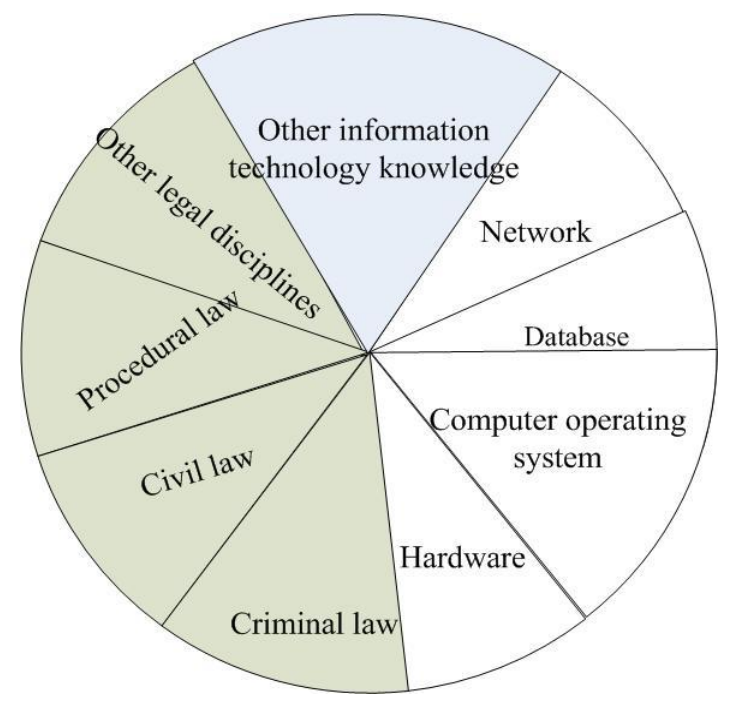

Fig. 1 Knowledge architecture 


\section{TRAINING METHODS OF INFORMATION TECHNOLOGY LAW TALENTS}

The cultivation of such talents both at home and abroad by the two ways to [2], see Fig. 2. One of them is the "nonacademic" culture, which is teaching lawyer or legal practitioners' computer knowledge, or the opposite. Both through the training, the corresponding certification qualifications, law enforcement process can be involved in computer and Internet related crime or disputes to the legislative activities, can also participate in some of the legislation. Another is the "degree" culture, is in the university students to undergraduate, masters, doctoral level education and training, the students not only learn computer knowledge, but also learn legal knowledge. The former method is obviously cultivation mode, shortage of law and computer talents can only be short-lived, while the latter is the fundamental way to solve these problems. As the most fundamental way of undergraduate education, because it not only provides the basic reserve talents for master, doctoral level training, and it can provide a lot of information technology related legal talents for the society.

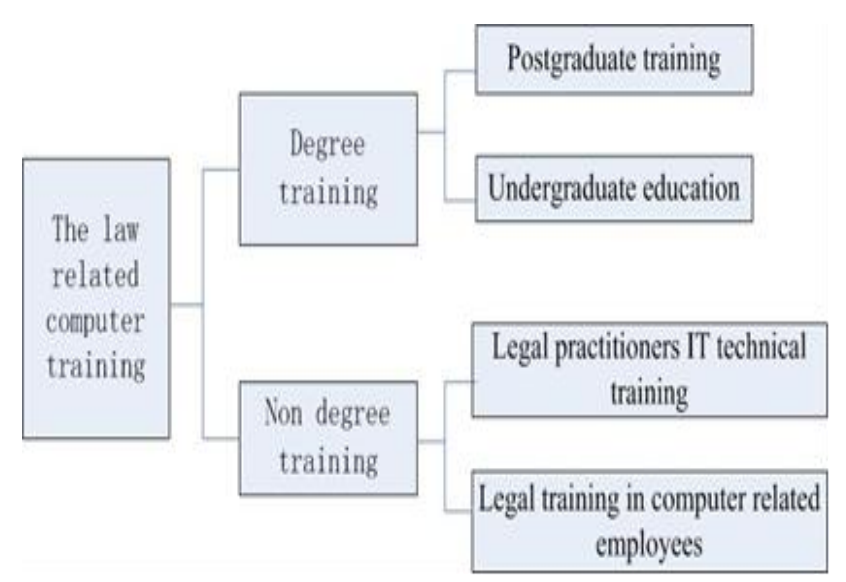

Fig. 2 training methods

\section{QUALIFICATION FOR MANAGEMENT TO INFORMATION TECHNOLOGY LAW TALENTS}

For related information technology law should be arranged visits appropriate qualification examination, and in the pass, to be qualified practitioners the ability to review the appropriate. For example, the information and the network crime forensics, both graduate students and social personnel, to obtain this field qualification should be through the "information and the network crime forensics qualification" examination, and regular random of capacity to employees; for information and network legislative staff only through the national judicial examination outside, should also be through professional "information and network legislation qualification examination and regular random", the workers should have the ability to review; through the national judicial examination and professional "information and network trial qualification examination for the" information and network criminal justice practitioners, and regular random ability for review; the development of the computer system in the Department of public security organs and other units of the staff should be through the national judicial examination. Due to the development of information technology is very fast, crime and disputes case new will never stop, so the relevant information technology legal personnel should periodically for new technology training; at the same time should also regularly for the latest laws and regulations training. See Fig. 3.

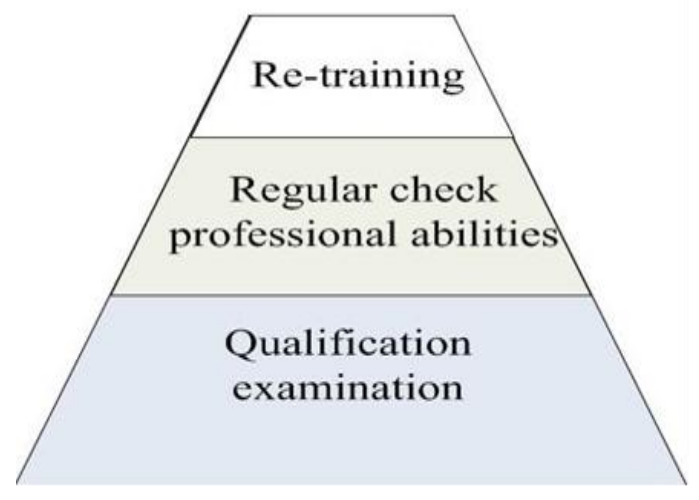

Fig. 3 qualification management

\section{DIFFICULTIES AND COUNTERMEASURES OF CULTURING INFORMATION TECHNOLOGY LAW TALENTS}

First difficulty is the problem of teachers. The teacher structure at present, either legal professional teacher, master of law related knowledge, or is a computer professional teacher, proficient in computer related fields of knowledge, but a serious lack of the master computer knowledge and mastery of legal knowledge of the teacher, in both education and fly degree education, this is a difficult problem.

Solution: a suggested solution is to have two kinds: one, the courses system law related courses teacher necessary computer knowledge training, so that teachers can grasp the related knowledge of information technology; two, the curriculum included as when computer related courses teacher necessary legal knowledge training, the teachers can master the basic knowledge of law. Establish a quality of law and computer talents of teachers.

Second difficulty is teaching materials. The current structure of teaching materials is legal professional disciplines of teaching materials, or computer professional subject teaching, they rarely interaction. That the students can grasp the knowledge of law and information technology, increase the difficulty and time of composite. 
Solution: by professor senior information technology related legal practitioners or university published as soon as possible with some law and information technology teaching materials, such as modified materials of legal professional, adding case information technology related; modify the information technology related materials, modify the comprehensive case, increase legal awareness.

Third difficulty is education in the curriculum. In order to realize the goal of training more relevant information technology law talents, usually have four options: first, based on the mature legal professional courses on computer courses, adding amount of; second, on the basis of professional course of computer of the mature legal courses, adding proper amount; third, simple the mature legal professional courses and mature computer professional courses together; fourth, the mature legal professional courses and professional courses of mature calculation for exclusion, combined with the training goal, the curriculum system healthy and reasonable. Obviously, the first, two kinds of realization is relatively simple, can be achieved in a comprehensive university in general, but their knowledge structure is not very reasonable, a kneading traces like water, gas, oil and water, the knowledge is separated, no system; third schemes although can let students learn two professional knowledge, they can cross, but need to go beyond the normal period of study, 5-6 years to complete these mature need professional course of study; the fourth kind of scheme is clearly the best, but how to mature curriculum courses are deleted, and even some chapters of course were cut, so that students master the basic computer knowledge and legal knowledge, knowledge structure system, healthy and reasonable.

\section{ACKNOWLEDGEMENTS}

The corresponding author of this paper is CHEN Hai-Yan. This paper is supported by Projects of the National Social Science Fund (No.06BFX051); Shanghai university training and selection of outstanding young teachers in special research fund (No.hzf05046).

\section{SUMMARY}

Based on the above system framework, The East China politics and Law University [4] to set up the computer science and technology course in 2005, in order to cultivate legal talents in information technology, in the course system construction, teaching material construction, teacher training, and student employment has achieved good results.

\section{REFERENCES}

[1] Chen Haiyan. Research on the stage of the compound talents of computer and law undergraduate. Computer education, 2009, volume (21): 76-78.

[2] Li Guangqian see strategy -- new thinking American information network security analysis through the "prism". People's post July 8, 2013 fifth version: 1-3

[3] Wang Yongquan, Jin Huifang, Liu Qin. A knowledge structure of "computer" and "legal" compound application talent and training approaches of. Journal of Beijing Electronics Science and Technology Institute, 2006 , Vol(14) :39-40

[4] East China University of politics and law. http://www.ecupl.edu.cn/ 